\title{
CONTEXTO DA CONTRIBUIÇÃO DE CÂNDIDO ARAGONEZ DE FARIA NA MODERNIZAÇÃO DAS DIAGONAIS BARROCAS
}

\author{
THE CONTEXT OF CÂNDIDO ARAGONEZ DE \\ FARIA'S CONTRIBUTION TO THE \\ MODERNIZATION OF THE BAROQUE \\ DIAGONALS
}

\section{CONTEXTO DE LA CONTRIBUCIÓN DE CÂNDIDO ARAGONEZ DE FARIA EN LA MODERNIZACIÓN DE LAS DIAGONALES BARROCAS}

VALÉRIA APARECIDA BARI ${ }^{1}$ RAUl FELIPE SILVA RODRIGUES ${ }^{2}$

\footnotetext{
${ }^{1}$ Doutora em Ciência da Informação pela Universidade de São Paulo (2008). Docente do Departamento de Ciência da Informaçáo (DCI) e do Programa de Pós-Graduação em Ciência da Informação (PPGCI) da Universidade Federal de Sergipe (UFS). Vice-Diretora do Centro de Ciências Sociais Aplicadas da Universidade Federal de Sergipe (CCSA/UFS). Líder do Grupo de Pesquisa em Leitura, Escrita e Narrativa: Cultura, Mediação, Apresentação Gráfica, Editoração e Manifestaçôes (PLENA), desde 2015. E-mail: valbari@gmail.com

${ }^{2}$ Graduando do curso de Artes Visuais, Licenciatura, da Universidade Federal de Sergipe (UFS). Membro do Grupo de Pesquisa em Leitura, Escrita e Narrativa: Cultura, Mediação, Apresentação Gráfica, Editoração e Manifestaçôes (PLENA). E-mail: rauldolago1@gmail.com
} 
RESUMO: Estudo sobre a vida e obra de Cândido Aragonez de Faria, enfatizando sua contribuição na modernização das diagonais barrocas, como recurso de comunicação da narrativa sequencial gráfica. Contribuiu para o jornalismo brasileiro e latino-americano, com impecável texto poliglota e imagens de rara expressão, levou a irreverência, a beleza e o humor de sua arte às propagandas de Paris da Belle Époque. Sua atuação, sempre pioneira e inédita, o colocou entre os melhores chargistas e ilustradores do mundo em sua época. No entanto, o Brasil da atualidade obnubilou sua lembrança e a França o tem para si como um patrimônio artístico, custodiado pelo Museu do Louvre e pela Biblioteca Nacional. O resgate de sua memória é importante para retomar a identidade brasileira de seu trabalho e abrir possibilidades de aprimoramento da composição barroca aplicada às narrativas sequenciais gráficas, como recurso de aprimoramento das mídias impressas e digitais no séc. XXI.

ABSTRACT: This is a study on the life and work of Cândido Aragonez de Faria, emphasizing his contribution to the modernization of baroque diagonals, as a communication resource of sequential graphic narrative. He contributed to Brazilian and Latin American journalism, with impeccable polyglot text and images of rare expression, took the irreverence, the beauty and the humor of his art to the advertisements of Paris from the Belle Époque. His performance, always pioneering and unprecedented, placed him among the best cartoonists and illustrators of the world in his time. However, today Brazil has obscured his memory and France has taken him as an artistic heritage, guarded by the Louvre Museum and the National Library. The retrieval of his memory is important in order to retake the Brazilian identity of his work and to open possibilities for the improvement of Baroque composition applied to sequential graphic narratives, to guarantee the improvement of digital media in the 21 th century.

RESUMEN: Estudio sobre la vida y la obra de Cândido Aragonez de Faria, destacando su contribución en la modernización de las diagonales barrocas, como recurso comunicativo de narrativa gráfica secuencial. Contribuyó al periodismo brasileño y latinoamericano, con textos políglotas impecables e imágenes de rara expresión, llevó la irreverencia, la belleza y el humor de su arte a los anuncios de París de la Belle Époque. Su actuación, siempre pionera y sin precedentes, lo colocó entre los mejores dibujantes e ilustradores del mundo en su época. Sin embargo, Brasil hoy ha oscurecido su memoria y Francia lo tiene como patrimonio artístico, custodiado por el Museo del Louvre y la Biblioteca Nacional. La recuperación de su memoria es importante para retomar la identidad brasileña de su obra y para abrir posibilidades de mejora de la composición barroca aplicada a narrativas gráficas secuenciales, para garantizar la mejora de los medios digitales en el siglo XXI.

PALAVRAS-CHAVE: Jornalismo no Brasil; Narrativa Sequencial Gráfica no Brasil; História do Cinema.

KEYWORDS: Journalism in Brazil; Graphic Sequential Narrative in Brazil; Cinema's history.

PALABRAS-CLAVES: Periodismo en Brasil; Narrativa Secuencial Gráfica en Brasil; Historia del Cine. 


\section{INTRODUÇÃO}

Cândido Aragonez de Faria — ou "o Faria", como chamado pelo pesquisador Antônio Luiz Cagnin (2000) - foi um dos mais proeminentes artistas brasileiros, no que concerne à narrativa sequencial gráfica, tendo contribuído para o jornalismo brasileiro e latino-americano com texto impecável e imagens de rara expressão. Poliglota, levou a irreverência, a beleza e o humor de sua arte às propagandas de Paris da Belle Époque. Sua atuação, sempre pioneira e inédita, o colocou entre os melhores chargistas e ilustradores do mundo em sua época. No entanto, o Brasil da atualidade obnubilou sua lembrança. Enquanto a França tomou para si as produçóes do mesmo como um patrimônio artístico, custodiado pelo Museu do Louvre e pela Biblioteca Nacional.

O presente artigo compóe uma série de estudos acerca da participação de Cândido Aragonez de Faria na modernização das diagonais barrocas, a partir da sua produção de cartazes para a primeira companhia cinematográfica do mundo. Sendo assim, buscamos contextualizar a atuação desse sergipano na condução de elementos preponderantes da estética barroca para a modernidade. Com isso, salientamos a importância de Faria no âmbito internacional, bem como expomos consideraçóes iniciais sobre uma característica da composição barroca tão presente nos dias atuais, principalmente em pôsteres e cartazes de cinema.

Para tanto, expressamos a biografia do artista que teve como auge sua atuação na produção de centenas de cartazes para o estúdio cinematográfico Société Pathé Frères, hoje custodiados pela fundação francesa Jérôme Seydoux-Pathé. Vale também o estudo da sua vida em comparação com a de outras personalidades importantes para sequência progressiva da produção artística nacional e internacional.

Desse modo, motivados pela inquestionável magnitude artística de Cândido, vemos sem sombra de dúvidas sua participação na modernização das diagonais barrocas. Assim como sua contribuição à reprodutibilidade técnica das artes e narrativas gráficas sequenciais, 
pela introdução da cromolitogravura nas Américas. Contudo, em sendo escasso o referencial teórico dessa composição diagonal, ao menos no âmbito nacional, focamos nossas consideraçóes ao contexto dos acontecimentos.

Em suma, diante dos fatos, evidenciamos a presença das diagonais barrocas na composição dos cartazes de Cândido Aragonez de Faria. Por conseguinte, relacionamos o termo "modernização" a processos de produção da imagem.

\section{UM TALENTO JUVENIL ATRAVESSA O CONTINENTE SUL-AMERICANO}

Estamos na primavera de 1856. Nas ruas do Rio de Janeiro da Belle Époque, um jovem caminha no bairro do Jardim Botânico em direção à Academia Imperial de Belas Artes, na Travessa do Sacramento. Carrega diversos materiais, está no meio de um projeto importante, mas não andou de carruagem. Observa, de passagem, as pessoas vivendo seu cotidiano, suas roupas, falas, gestos, aparência. Ele mesmo, um jovem diferente dos fluminenses, tem os cabelos bem encaracolados de um louro acinzentado.

Figura 1: Cândido Aragonez de Faria em charge de Valle

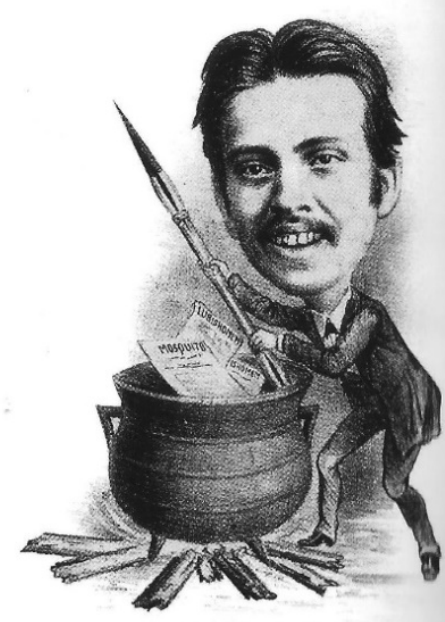

Fonte: O Mosquito, n. 83, de 14/04/1871 (MAGNO, 2012, p. 218).

A pele bronzeada pelo sol de Laranjeiras, município sergipano que foi sua cidade natal, enfatiza sua origem multirracial, que se confirma em olhos amendoados, com uma 
significativa epicântica asiática e o rosto redondo característico dos descendentes dos indígenas, ao mesmo tempo "ornamentado" com um bigode digno do rei Carlos I da Espanha $^{3}$ (Figura 1). Esse jovem, anônimo na corte imperial e fruto do casamento entre um grande médico sergipano e uma jovem imigrante espanhola, será, dentro de poucos anos, um dos mais proeminentes artistas gráficos do mundo.

Mas, qual seria esse grande projeto que, em paralelo com os seus estudos de Belas Artes, proporcionaria a elevação de Faria ao patronato que hoje ocupa no Brasil e no mundo? Essencialmente, narrativas sequencias gráficas, caricaturas e desenhos naturalistas que começou a oferecer aos grandes jornais da corte. Em suas longas caminhadas, ele se permitia ingressar nas sedes jornalísticas, fazendo um lento trabalho de reconhecimento e auxiliando em pequenas tarefas. A economia familiar de Faria, então contemplado com uma pensão pelo governo imperial, ia muito bem, então os editores também abriam espaço para o talentoso rapaz — por uma contribuição financeira irrisória, embora muito convidativa. Ainda mais, um jovem polivalente, que escrevia tão bem em português, assim como já tinha domínio do francês e do espanhol.

Figura 2: Autorretrato de Faria na capa de O Mosquito

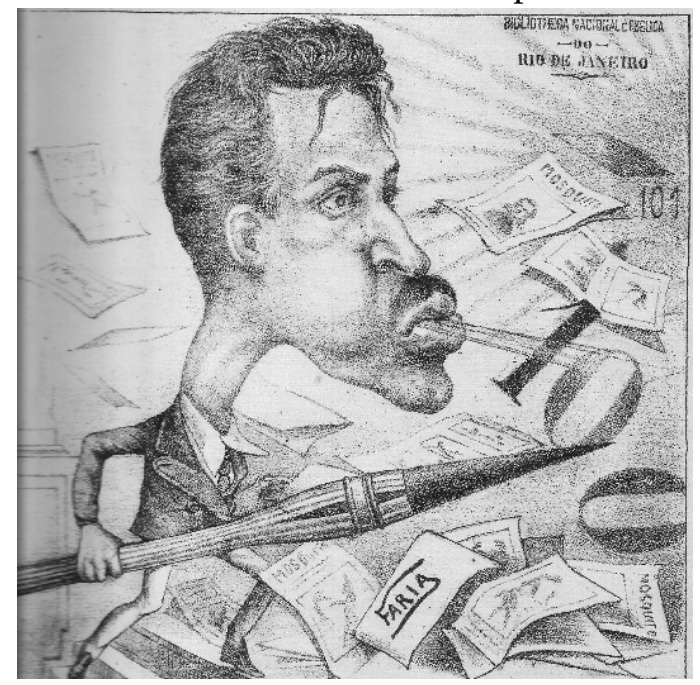

Fonte: Capa comemorativa da edição n. 100 de O Mosquito, em 12/08/1871 (MAGNO, 2012, p. 218).

\footnotetext{
${ }^{3}$ Herdeiro de três das principais dinastias europeias: a Casa de Habsburgo, a Casa de Valois-Borgonha dos Países Baixos Borgonheses e a Casa de Trastâmara das coroas de Aragão e Castela. Ele governou vastos domínios na Europa central, oriental e do sul, além das colônias espanholas nas Américas. Como o primeiro monarca a governar Castela, Leão e Aragão simultaneamente, ele se tornou o primeiro rei da Espanha. Trouxe a moda e a própria denominação do bigode para as Américas.
} 
Ao terminar oficialmente seus estudos, em 1866, começou a assinar matérias e conteúdos nos jornais A Pacotilha e Folha Fluminense. Fundou, com seu irmão Adolpho Aragonez de Faria, que viria a se tornar um fotógrafo extremamente conceituado, o jornal O Mosquito (Figura 2).

Para Magno:

Sob a tutela do Juiz de Órfãos, o jovem artista começou a colaborar na imprensa ilustrada. Surgiu como chargista de $A$ Pacotilha (que depois se denominou $O$ Pandokeu), no Rio, em 1866. Fundou e dirigiu o semanário $O$ Mosquito (1869), cabendo-lhe por certo tempo a exclusividade das ilustraçóes e da propriedade. Depois de passar por $A$ Vida Fluminense, lançou em 1874 outro semanário, O Mephistópheles, que circulou até 1875 . Nesses dois anos, a publicaçáo foi inteiramente ilustrada por ele (MAGNO, 2012, p. 218).

Toda a sua movimentação denota que criava espaço para garantir sua total liberdade de expressão e, por conseguinte, dedicar-se primordialmente ao humor, à paródia e à sátira política. Em 1869, Faria foi “emancipado” pela Coroa Brasileira, antes de completar 21 anos. Essa se caracterizaria como a primeira retaliação do governo imperial, em virtude do criticismo de sua produção. Compreenda-se que Faria recebera até então uma pensão que lhe garantia a subsistência, sendo órfão de mãe e pai, que foi abruptamente interrompida. Nessas circunstâncias inesperadas, preocupou-se cada vez mais com os aspectos profissionais de sua produção, pois se tornava essencial à sua sobrevivência, exigindo então remunerações mais adequadas para seus trabalhos.

\section{A EMANCIPAÇÃo de FARIA na CORTE FLUMINENSE}

A rebeldia de Cândido Aragonez de Faria o impedira de ter destino mais agradável do que alguns de seus conterrâneos, como Horácio Hora, também de Laranjeiras (SE). Alguns anos mais jovem, seguindo os mesmos passos de Faria, Hora se dedicou às Belas Artes e também à narrativa sequencial gráfica do jornalismo de sua época, assim como teve instruçôes e influência de Ângelo Agostini. Contudo, ao invés de "emancipado", recebeu 
bolsa de estudos da Coroa Brasileira para cursar a Escola de Belas Artes de Paris. As razóes e os critérios para esse tratamento distinto se tornam claras, ao verificamos as características da produção de Aragonez de Faria:

Faria protagonizou esta primeira fase da caricatura brasileira, que compreende cerca de meio século da vida política no Segundo Reinado, período que se caracterizou pela ferrenha oposição ao governo, e cuja sátira e verve do esfuminho visavam, sobretudo, os chefes de gabinete dos ministérios imperiais e a própria figura do Imperador, que reagia com "absoluta isenção de ânimo" aos ataques que recebia. As caricaturas de Faria, de grande valor historiográfico, comentam alguns importantes fatos da política dos gabinetes do Império, sobretudo o modelo político centralizador e apaziguador de D. Pedro II que, para manter o país distante de revoltas e revoluçóes, alternou agrados e benefícios políticos, ora ao Partido Conservador, ora ao Partido Liberal (GAUDÊNCIO Júnior, 2015, p. 37).

Como um fator de reciprocidade, a impressionante passagem de Horácio Hora por Paris e posteriores retornos tenham aberto passagem para que Cândido Aragonez de Faria e seu irmão Adolpho, mais velhos e experientes, pudessem fixar-se como profissionais na França de modo permanente.

Nesse momento histórico da narrativa sequencial gráfica no Brasil e, atrevemo-nos a dizer, no mundo, o modo de produção partia de uma lógica diferenciada das Artes Plásticas em geral. Sendo matéria de inovações e, posteriormente, de estudos, acompanhou a dinâmica das tecnologias gráficas. Portanto, a produção de ilustraçôes, charges, artes, capas, caricaturas e histórias em quadrinhos primitivas ressignificou modelos artísticos predecessores.

$\mathrm{Na}$ verdade, Ângelo Agostini orientava as produçóes de seus aprendizes disponibilizando artes anteriormente publicadas, de sua autoria e de outras origens, lhes ordenando as adaptaçóes. Se por um lado isso acabou por criar um padrão de qualidade, arte-finalização e dimensóes adequadas para elaboração de narrativas gráficas, por outro lado prejudicou significativamente a questão da autoria das produçôes. Esse modo de produção acompanhava toda a produção jornalística que, no eixo Rio de Janeiro e São Paulo, se encontrava liderada por estrangeiros, que traziam essa cultura da Europa. Segundo Gaudêncio Júnior: 
A propalada influência estrangeira muitas vezes esbarrava nos empréstimos, nas similitudes decorrentes da apropriação do trabalho de outro, prática comum nesta época, pois devido à ampla circulação de imagens tecnicamente multiplicadas, questóes como "cópia" e "originalidade" adquirem outro estatuto no período aqui estudado, colocando em xeque questóes como marca individual e autoria (GAUDÊNCIO Júnior, 2015, p. 37).

Dada situação, segundo Hermann Lima, chegou a respingar a produção de Aragonez de Faria, pois o costume o levou a inspirar-se e aproveitar excessivamente as narrativas sequenciais gráficas publicadas na imprensa francesa. Outrossim, a leitura de diversos periódicos importados entre a corte fluminense, como o "Petit Journal Pour Rire", levou leitores e colegas de profissão a acusar diretamente Aragonez de Faria de plágio de artes de Alfred Grévin:

O próprio Faria chegou a reproduzir desenhos de Grévin na capa d'O Mosquito. Houve, inclusive, uma troca de acusaçóes entre O Mosquito e A Vida Fluminense, em que a segunda, em um trocadilho espirituoso, afirmou que a primeira "Faria muito melhor se não entretivesse relaçóes tâo íntimas com o Petit Journal pour Rire", publicação francesa muito apreciada na época (LIMA, 1963, p. 812, apud GAUDÊNCIO Júnior, 2015, p. 37).

Lição aprendida, restou à Aragonez de Faria a tarefa de aprimoramento de seu traço, o caminhar para a independência em relação aos modelos e a estilização que marcaria sua autoria de forma indelével, desgarrando-se paulatinamente das soluçóes "práticas" apontadas por Ângelo Agostini (Figura 3). Consagrado na imprensa brasileira nos anos 1870, concomitantemente com problemas e dores irreconciliáveis na vida pessoal ${ }^{4}$, Cândido Aragonez de Faria se prepara para expandir seus horizontes, se desapegando da imprensa fluminense.

\footnotetext{
${ }^{4}$ Embora a literatura especializada não enfatize a efeméride da morte prematura da primeira esposa de Faria, Beatriz Emília da Rocha Faria, como ponto de inflexão de sua carreira. Casando-se com ela em 1871, quando a mesma contava com 16 anos, viu seu desaparecimento em novembro de 1874. A partir desse momento, a vida pessoal de Cândido Aragonez de Faria foi eclipsada por anos, com redobrada dedicação ao trabalho, energia inventiva, consolidação de estilo e técnica, busca de novas topologias, além da formação de uma geração de aprendizes.
} 
Figura 3: Ferreira de Menezes se autorretrata limpando o nariz dos bebês chorôes Agostini e Faria

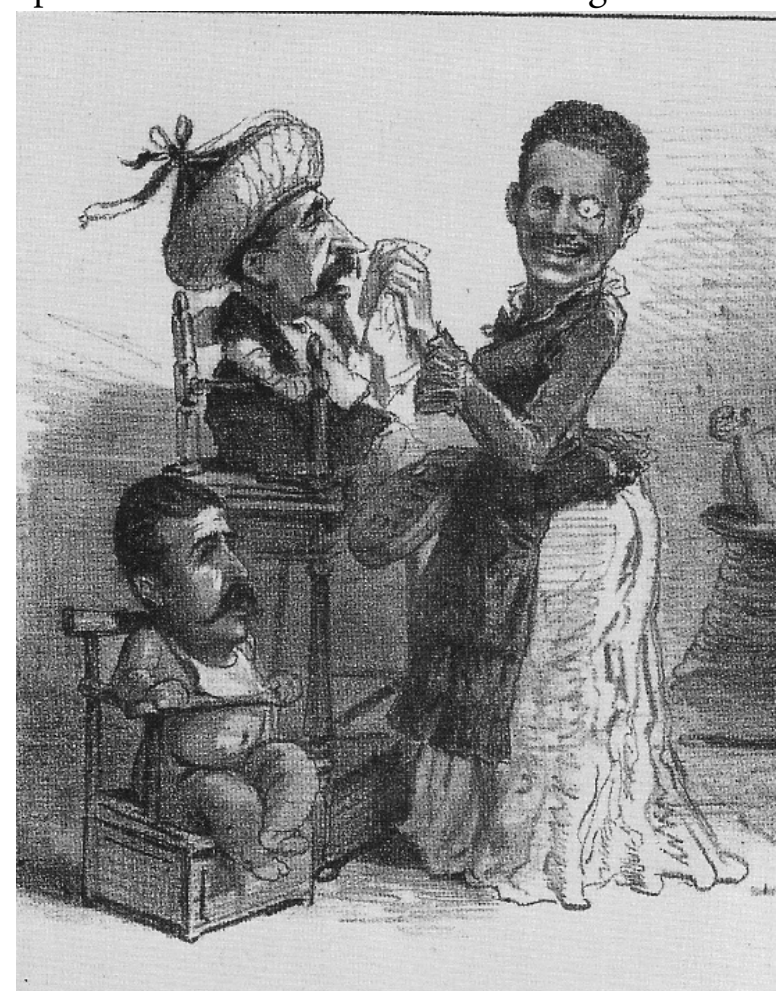

Fonte: Detalhe da capa de O Fígaro, n.7, de 12/02/1876 (MAGNO, 2012, p. 434).

A partir de 1874, a extrema dedicação às publicações $O$ Mosquito e $O$ Fígaro $^{5}$ se transfigura no momento de maior representatividade de Faria. Mas, em 1878, abandona a corte e faz uma viagem de trabalho e estudos a Porto Alegre. Após um ano, sai do Brasil e passa um longo período em Buenos Aires, concretizando o projeto de publicação da primeira revista colorida das Américas, La Cotorra, em outubro de 1869 (Figura 4). Segundo Magno:

A pesquisadora [argentina Diana Cavallaro] ressalta que La Cotorra "não apenas contribuiu com a comicidade e a agudeza de suas observaçóes, como se inscreveu na história do jornalismo argentino por seus próprios esforços: produto de qualidade cromolitográfica alcançada pela imprensa nacional, as caricaturas coloridas de suas capas foram um verdadeiro avanço em nosso país e em toda a América Latina" (MAGNO, 2012, p. 226).

\footnotetext{
${ }^{5}$ O Fígaro foi outro proeminente semanário da corte fluminense, que Faria chegou a assumir integralmente a parte gráfica no ano de 1876 (MAGNO, 2012, p. 218).
} 
Desde o lançamento da revista, e ao longo dos primeiros 43 números, Aragonez de Faria foi o ilustrador exclusivo dessa publicação. A partir de tal empreitada, Faria se consagrou um dos pioneiros da imprensa nas Américas, inclusive convertendo a direção dos eixos de influência para os Estados Unidos, Portugal, Espanha e França.

Figura 4: Página central do periódico argentino La Cotorra, ilustrado por Faria

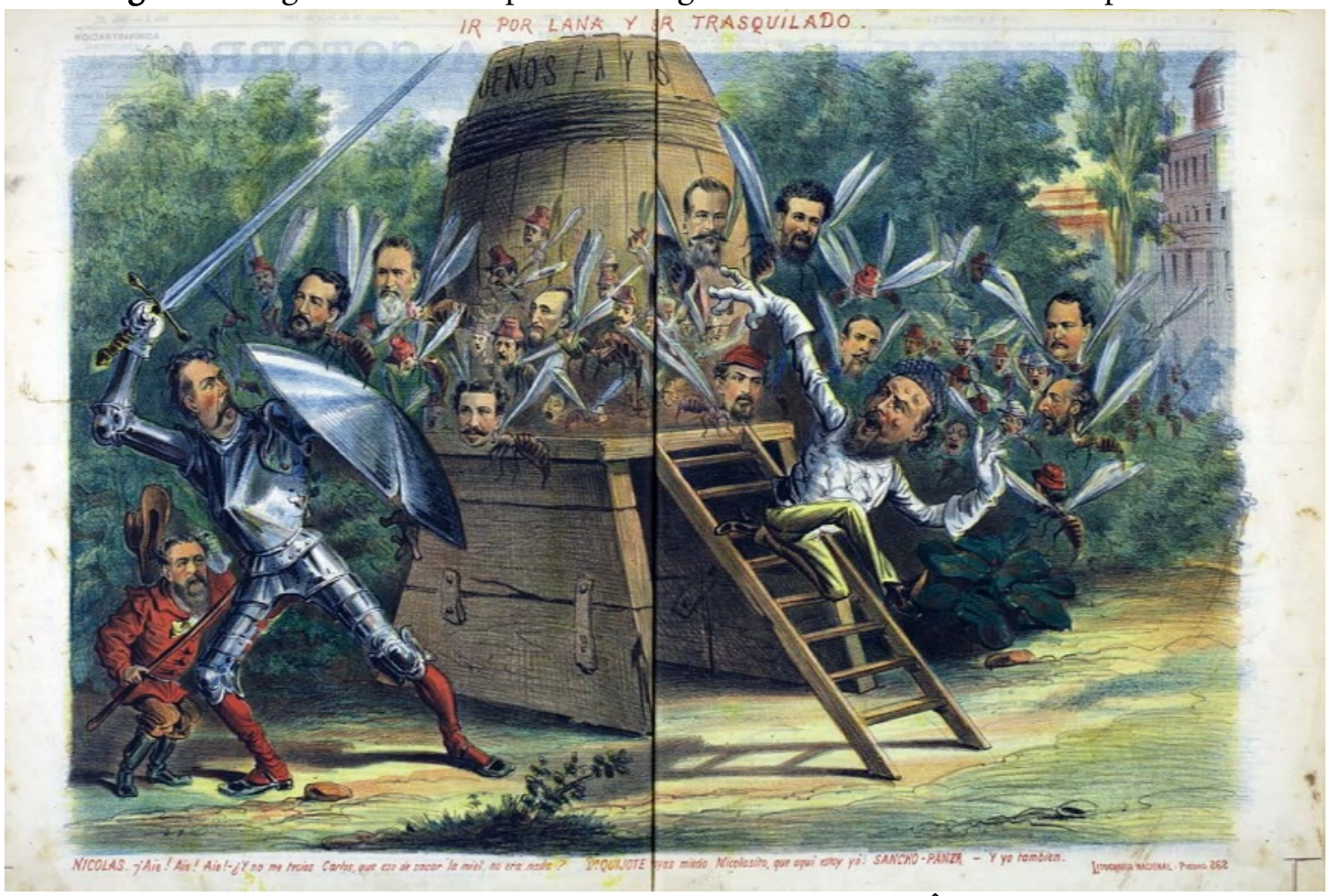

Fonte: Página dupla central de La Cotorra, de 20/06/1880 (CÂNDIDO, 2018).

Aqui, consideramos que o amadurecimento de Faria o levou a implantar no Brasil os recursos gráficos já preexistentes da litografia $^{6}$ para garantir o acesso e comercialização massiva das artes coloridas em suporte de papel, sem necessidade da aplicação manual das cores sobre uma impressão em preto e retículas (tons de cinza).

Essa inovação foi fruto da visão de Faria sobre as impressôes, que vislumbrou o amadurecimento do olhar dos leitores e a contemplação de um mercado consumidor mediante a criação dessas necessidades estéticas. O legado de Faria permite observar que a

\footnotetext{
${ }^{6}$ Litografia é o método de impressão desenvolvido em 1798 por Aloys Senefelder, no qual a imagem é desenhada com lápis ou tinta apropriada em pedra ou material adequado. $\mathrm{O}$ processo é baseado na incompatibilidade entre a graxa e a água. Coloca-se uma folha de papel sobre a pedra e a prensa litográfica; como resultado obtém-se uma réplica exata, mas invertida da imagem no papel. Já na cromolitografia utilizase uma pedra ou prensa para cada cor (CHILVERS, 1996, p. 311-312).
} 
busca pela inovação das artes gráficas com êxito comercial foi uma constante de seu trabalho, já que o seu traço havia chegado ao amadurecimento; e o domínio das cores viera de sua sólida formação em Artes Plásticas.

Na Europa, a impressão colorida já era praticada desde 1837, quando o alemãofrancês Mulhouse patenteou o modo de produção da cromolitogravura. A separação de matrizes de impressão em cores primárias e preto garantiam a impressão colorida, com grande durabilidade (MENEZES, 2008). Porém, a impressão tornava-se mais complexa e exigia prensas precisas, assim como a regulagem constante, melhor qualidade do papel, etc.

Então, se a fruição da revista colorida tinha um custo, Faria acreditou que os leitores arcariam com esse custo, para viver a experiência em todos os aspectos de contemplação, informação, diversão e significação. Suas expectativas se confirmaram, pois o produto foi comercializado e trouxe consigo uma nova tendência de produção editorial para a Argentina. Dessa forma, as experiências de Faria iniciaram uma relação diferenciada com a Arte na América do Sul, a partir das últimas décadas do séc. XIX, consolidando-se ao longo do séc. XX. Segundo Walter Benjamin (1990), que denominaria essa propriedade de Reprodutibilidade Técnica:

Poder-se-ia dizer, de modo geral, que as técnicas de reprodução destacam o objeto reproduzido do domínio da tradição. Multiplicando-lhe os exemplares, elas substituem por um fenômeno de massa um evento que não se produziu mais do que uma vez. Permitindo ao objeto reproduzido oferecer-se à visão e a audição em qualquer circunstância, elas lhe conferem uma atualidade. Esses dois processos conduzem a um considerável abalo da realidade transmitida: ao abalo da tradição, que é a contraface da crise que atravessa atualmente a humanidade e a sua atual renovação. Eles se mostram em estreita correlação com os movimentos de massa que hoje se produzem (BENJAMIN, 1990, p. 213-214).

Em pouco anos, contudo, Faria sente que ainda não está instalado, não criou raízes na Argentina. La Cotorra havia "sido fechada" pela censura do presidente Roca em 1880, dilapidando seus investimentos e mesmo seus recursos de sobrevivência. Pronto para mais um passo arrojado, se alia a seu irmão Adolpho, para abertura de um escritório de representação em Paris, por volta de 1883, onde elevaria a sua produção a outro nível. Enquanto seu irmão se dedica à fotografia - arte também aprendida nos espaços 
acadêmicos brasileiros - Faria vai demonstrar seu traço autoral e domínio da cromolitogravura; ainda mais, vai fundamentar com seu trabalho como contribuição à modernização da estrutura compositiva barroca.

\section{A MODERNIZAÇÃO DA ESTRUTURA COMPOSITIVA BARROCA NA PRODUÇÃO DE FARIA}

A relação de Faria com Horácio Hora o coloca num círculo de amizades especialmente vinculado à Academia de Artes de Paris. Disponibilizando para si um grupo de artistas jovens, preparados para assessorar a produção de toda a natureza de narrativas gráficas e de impressos. Segundo os estudos de Gaudêncio Júnior, Ângelo Agostini continuava cuidando de seus aprendizes, indo em busca de notícias dos mesmos na distante Paris. Naquele momento, Faria, Hora e jovens do Brasil inteiro se instalavam na urbe parisiense, certamente devendo parte de seu êxito ao jornalista e artista gráfico italiano:

Novas notícias vieram com a descoberta de uma antiga carta de Ângelo Agostini, datada de Paris, de 4 de dezembro de 1889. Nela, o nome maior de nossa caricatura relatou o agradável encontro que teve na capital francesa com vários pintores brasileiros, dentre eles Vítor Meireles, Lopes Rodrigues, Eduardo de Sá e o já citado sergipano Horácio Hora. Segundo Agostini, além destes,

Também estive com nosso antigo colega Faria, que ficou contentíssimo de ver-me. Este não faz pinturas; dedicou-se ao desenho, no qual têm feito enorme progresso e tem, hoje, trabalhado a valer para várias ilustraçôes. É muito procurado e faz bom negócio (AGOSTINI apud GAUDÊNCIO Júnior, 2015, p. 61).

Cândido Aragonez de Faria de fato não estava interessado no mercado da pintura, dominado por artistas europeus que conservavam grandes vínculos com a aristocracia e se mantinham financeiramente devido à uma produção artística serviçal, num esquema muito antigo e consolidado de mecenato. Definitivamente, sua produção desde a adolescência, muitas vezes, entrara em choque com a estrutura sociopolítica instituída. 
Naquele momento, a estética da pintura enveredara pela chamada escola simbolista, e Paris estava à frente, com Paul Gauguin e outros ativistas, em busca de uma representação artística que se descolasse da imagem realista, em direção à realidade ampliada do pensamento, imaginação e simbologia imagética. Isso tudo se colocava como anteparo à imprensa e à publicidade, que buscavam uma precisão imagética e a representação da realidade, de forma convincente para o leitor. Então, Faria foi buscar no academicismo italiano apreendido em seu passado, a dramaticidade necessária às imagens que produziria.

As características da pintura barroca foram eleitas por Faria como as ideais para a representação da realidade, trazendo ao mesmo tempo movimento e efeitos dramáticos que a faziam mais expressiva que a fotografia. Quando se tratava de fotografia, seu irmão e agora sócio Adolpho chegara aos limites da excelência e tornava para Cândido muito claro o campo da disputa imagética aonde iria firmar os alicerces de seu trabalho. O pintor barroco Agostino Carracci $^{7}$ inovou a narrativa gráfica na imprensa europeia, com a invenção da caricatura, seu sobrinho Annibale é o autor da icônica caricatura de Charles Darwin (Figura 5), numa crítica à Teoria da Evolução. Todas essas evidências influenciaram o caminho de Faria, que seguiu sabiamente a tendência.

\footnotetext{
${ }^{7} \mathrm{O}$ termo "caricatura" apareceu pela primeira vez em 1646, com finalidade de nomear as séries de desenhos satíricos de Agostino Carracci. Seu sobrinho, Annibale Carracci (homônimo do irmão mais velho de Agostino) foi um dos grandes expoentes da caricatura. É o pioneiro na História da Arte a utilizar-se dela, contrapondo-a à idealização da figura humana. $\mathrm{Na}$ imprensa, Annibale fez as caricaturas mais famosas do séc. XIX (CARICATURA, 2018).
} 
Figura 5: Caricatura de Charles Darwin por Annibale Carracci

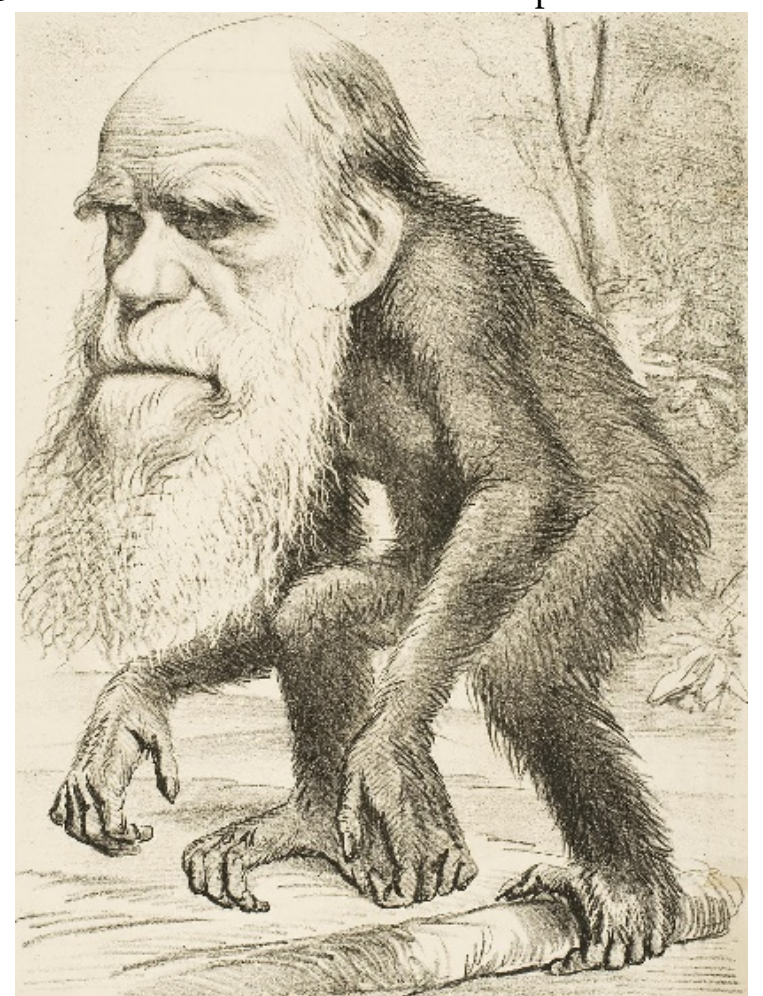

Fonte: Charge de Charles Darwin, publicada na Revista Inglesa The Hornet em 22/03/1871 (DARWIN, 2018).

A estrutura compositiva barroca, criada no séc. XVII, prevê a utilização de diagonais condutivas da imagem, com o intuito de lhe conferir maneirismo e movimento. É considerada muito dramática e exagerada, ainda mais porque os pintores desenvolveram técnicas de ilusão de ótica, que são incorporadas para dar maior sensação de vida e movimento às imagens, retratadas de modo realista e anatomicamente perfeito. A composição barroca é assimétrica, em diagonal, e se revela num estilo grandioso, monumental, retorcido, substituindo a unidade geométrica e o equilíbrio da arte renascentista (PINTURA, 2018).

Ainda podemos verificar que, seguindo a própria definição da cultura italiana, sua arte apresentara duas diagonais que entrecruzavam e criavam efeitos perceptíveis: a diagonal barroca, da direita para a esquerda, e a diagonal sinistra, da esquerda para a direita. Como a própria língua italiana determina, tudo o que vem da esquerda necessariamente carrega 
consigo o peso da negatividade. Em uma definição enciclopédica, o conceito de sinistro ${ }^{8}$ aponta para o acidental, o prejuízo, o malefício, a presença do demônio. Em português, o termo nos chegou sem a conotação da direção esquerda, mas Faria conhecia muito bem esse conceito e resolveu aplica-lo em sua arte, para realçar a emoção e a dramaticidade.

Segundo Mattos, as diagonais barroca e sinistra são hoje recursos viáveis à composição de cartazes, indicando emoçóes negativas:

O fato é que, em uma composição, uma diagonal muito marcante pode ser capaz de alterar sua percepção ou suas emoçôes dependendo da forma em que elas estão direcionadas. [...] A diagonal sinistra é aquela que normalmente tem o seu ponto mais alto no topo esquerdo da composição e o ponto mais baixo na base direita da composição dependendo da forma que você estrutura seu grid. [...] Essa diagonal tende a oferecer uma leitura agressiva e incômoda para nós. Teoricamente elementos que acompanham essa diagonal não nos despertam boas sensaçôes. [...] Isso provavelmente tem a ver com a nossa forma de leitura, principalmente a ocidental, e também com a nossa percepçáo sobre a ideia de gravidade (MATTOS, 2017, p. 8-11).

Ao ser contratado para a elaboração do primeiro cartaz da recém aberta Société Pathé Frères, para anunciar o filme chamado "As Vítimas do Alcoolismo", elaborou uma imagem central com estrutura renascentista, isso é, uma cena posada em forma geométrica solida, triangular e estável, mas inseriu pequenos quadros com estrutura compositiva barroca, terríveis diagonais sinistras nos cantos do cartaz, mostrando o desenlace trágico do filme (Figura 6).

\footnotetext{
${ }^{8}$ Sinistro é uma palavra com origem no termo em latim sinistru e significa esquerdo, funesto, ameaçador, assustador, desgraçado. Também pode ser sinônimo de desastre, acidente, grande prejuízo ou naufrágio. Disponível em: < https://www.significados.com.br/sinistro/>. Acesso em 25/02/2018.

9 Tradução livre dos autores para o título "Les victimes de l'alcoolisme", de 1902.
} 
Figura 6: Cartaz do filme "As Vítimas do Alcoolismo”, com composição renascentista ao centro e barroca nas laterais

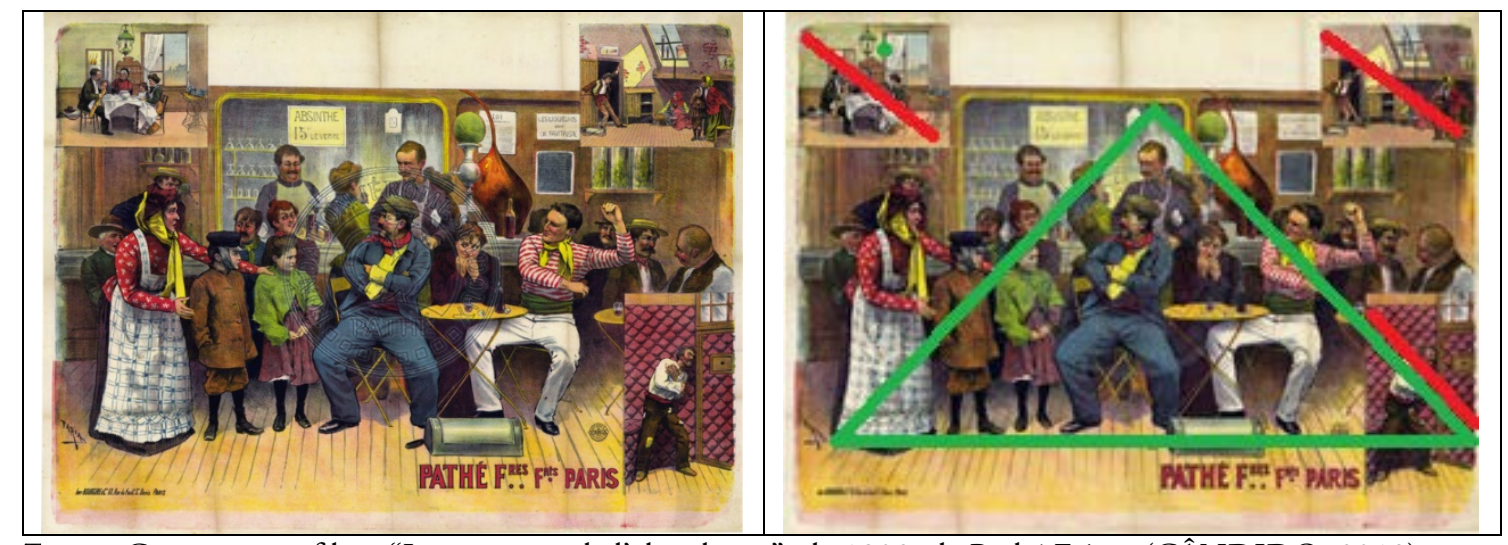

Fonte: Cartaz para o filme "Les victimes de l'alcoolisme", de 1902, da Pathé Frères (CÂNDIDO, 2018) e diagrama de Raul Felipe Silva Rodrigues.

A visão do cartaz ricamente colorido, pregado nos muros parisienses, levou uma multidão às salas de exibição. Refinando as solicitaçóes iniciais, Faria aplicaria cada vez com mais êxito as diagonais sinistras, anunciando filmes com fortes emoções e tragédias (Figura 7).

Figura 7: Cartazes de Faria para os estúdios de cinema Pathè Frères

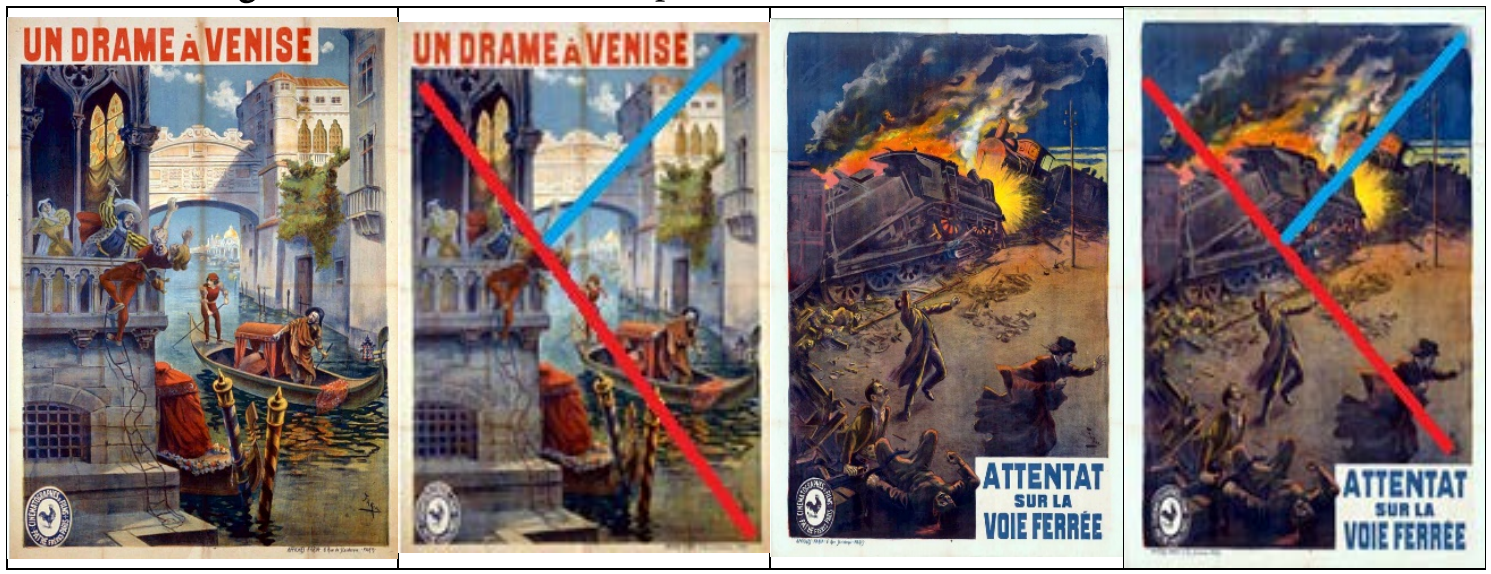

Fonte: Cartazes para os filmes "Un Drame à Venice" e "Attentat sur la Voie Ferrè", acervo da Biblioteca Nacional da França (GALLICA, 2018) e diagramas de Raul Felipe Silva Rodrigues.

Porém, mais à frente, verificou que o tempero da presença da diagonal sinistra ainda fazia o cartaz mais chamativo, como a promessa de quebra do tédio e a vivência das emoçóes que o filme ou espetáculo podiam proporcionar, independentemente de um final feliz ou funesto (Figura 8), enfatizando, porém, os conteúdos para adultos. 
Figura 8: Cartazes de Faria com anúncios de apresentaçóes de artistas

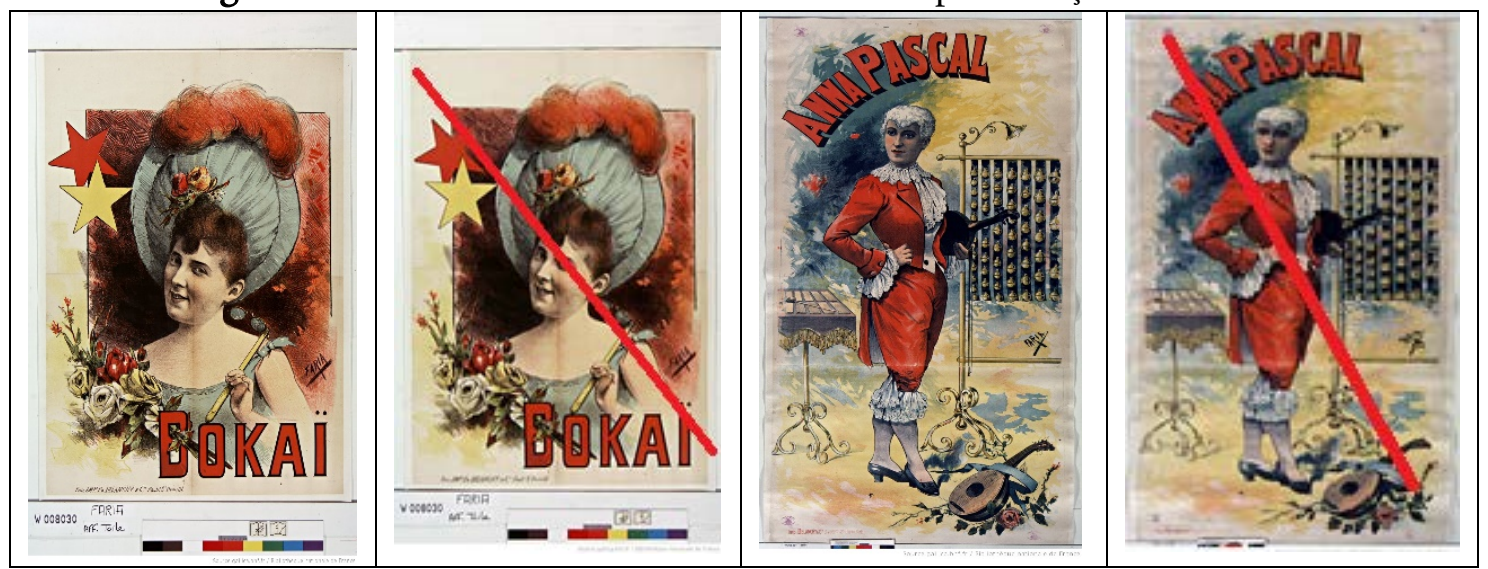

Fonte: Cartazes Bokai e Anna Paschoal, acervo da Biblioteca Nacional da França (GALLICA, 2018) e diagramas de Raul Felipe Silva Rodrigues.

A amostra dos cartazes preservados nos permite a visualização dessa evolução e de tudo o que ela trouxe para a narrativa gráfica sequencial e para a publicidade, sob o pioneirismo de Cândido Aragonez de Faria.

\section{O OSTRACISMO NO BRASIL E APAGAMENTO DA IDENTIDADE BRASILEIRA DE FARIA NA FRANÇA}

A vida em Paris, no bairro de Montmartre, foi continuamente dedicada ao trabalho, embora Faria tenha voltado a se interessar pelo relacionamento amoroso e reconstituído uma família parisiense. Porém, de modo diferente à experiência de sua juventude, pouco se dedicou à esfera doméstica, tendo a maior parte do tempo dispendida ao seu atelier. De fato, falece executando o seu último trabalho, um cartaz retratando uma bela vedete, que posava para ele naquele momento:

Cândido Aragonez de Faria faleceu trabalhando em 17 de dezembro de 1911. Acredita-se que realizava um retrato da vedete do café concerto Eugénie Buffet. [...]

Após ter, por seu labor obstinado - durante quarenta anos contribuido à ressurreição de uma arte e de uma indústria mais florescente que nunca na época atual; após ter aguçado o gosto do público pela litografia e feito uma grande quantidade de profissionais viverem de seu lápis litográfico, cujo trabalho diário só se originava de sua produção de artista, Faria se foi, em uma manhã cinzenta de inverno, para o país de onde não se volta mais. Naquela manhä, um 
domingo, o velho mestre de imagens, assim ele teria sido chamado na Idade Média, trabalhava em seu ateliê, na rua de Steinkerque. Estava sozinho. $O$ ar vibrava com o carrilhão dos sinos. Ele trabalhava. De repente, seus dedos não enlaçaram mais a palheta, subitamente pesada demais, a mão escorregou, e a fronte branca se inclinou sobre a obra inacabada... ... Faria estava morto em seu cavalete, como um soldado, sob as armas (VERHILLE apud GAUDÊNCIO Júnior, 2015, p. 330).

Seu filho Jacques Aragonez de Faria, nascido em Paris no ano de 1898, assume os trabalhos e o estilo do pai. Jacques falece em 29 de janeiro de 1956, ocasião pela qual são encerradas as atividades do estúdio de Montmartre. Na cultura francesa, também é classificado como pintor. Foi o filho de Jacques, Felipe Aragonez de Faria, que se responsabilizou posteriormente pela revitalização da memória do avô Cândido, sensibilizado pelo pesquisador brasileiro Antônio Luiz Cagnin.

No Brasil da década de 1910, o falecimento de Cândido Aragonez de Faria não mereceu nota, pois o artista já havia sido morto e enterrado muito antes, na memória da intelectualidade brasileira. A Argentina, igualmente, o havia esquecido, pois não existe fonte pesquisável nem na atualidade sobre La Cotorra além dos originais preservados nos acervos de obras raras da sua Biblioteca Nacional. Contudo, aos poucos, seu nome foi ressurgindo do ostracismo, forçosamente despontando por meio de sua produção paradigmática.

Depois que deixou o Rio, em 1878, aparece seu nome, por extenso, no Catálogo da Exposição de História do Brasil, de 1881. Num prolongado silêncio de muitos anos, só em 1917, Max Fleuiss, no artigo "A Caricatura no Brasil”, mencionou, mas táo somente, o sobrenome Faria. Em 1922, em rápida referência, porém, é Raul Pederneiras que, numa de suas crônicas, com toda autoridade de grande caricaturista, incluiu Faria entre "os verdadeiros prodígios do lápis". Gonzaga Duque, em 1929, também, como Fleuiss, não lhe ultrapassa o sobrenome.5 Nada mais. Dez anos depois, em 1939, Ruben Gill, autoridade quanto aos caricaturistas brasileiros do presente século (XX) na sinopse dos "Caricaturistas do Rio de Janeiro", nem sequer o menciona e, mais grave, levado pela semelhança do sobrenome, atribui, erroneamente, ao pintor Leopoldino de Faria o título de iniciador da caricatura no Brasil, que, de direito, cabe não a outro Faria que ao Cândido. Em 1941, Gondin da Fonseca, como os demais, se limita a citar-lhe o nome, e assim mesmo abreviadamente, e lhe acrescenta ao lado algumas obras: "FARIA (C. A. de) - O Mosquito, O Diabrete, A Vida Fluminense, O Zigue-Zague. 
Somente em 1954, Hérman Lima lhe reserva estudo mais alentado no artigo "Cândido de Faria, um Mestre Esquecido" (CAGNIN, 2000, p. 3)

Enquanto isso, no continente europeu, a obra é preservada e disseminada até o presente momento, porém existe certo ocultamento da identidade brasileira do trabalho e estilo, sendo sua preservação tratada como se fosse um imigrante ou descendente que tudo tivesse aprendido, obtido e sintetizado em território francês. A memória e a cultura francesa enfatizam a influência da produção de Henri de Tolouse-Lautrec, que fora em sua época um concorrente talentoso na categoria dos cartazes (affiches), porém desregrado. Henri faleceu em 1901, tendo como invenção inédita com certeza a fórmula do coquetel "Terremoto" ${ }^{10}$. A síntese de Tolouse-Lautrec entre a figuração ocidental e oriental é considerada excelente, mas não foi o trabalho mais significativo em matéria da produção de cartazes em sua época, nem mesmo em seu bairro de moradia, o Montmartre. Ali, se procurava como primeira opção o estúdio de Cândido Aragonez de Faria, até a sua morte em 1911.

Então, embora sem o devido registro pela cultura francesa, desde as mais populares atrações dos cafés até a mais importante mídia criada no final do século XIX, o cinematógrafo, todos realmente procuravam o Faria para criar os cartazes utilizados na divulgação (affiches publicitaires). A Sétima Arte, nesse caso, foi servida por um profissional da Nona Arte, pois a narrativa gráfica deveria fazer parte da mensagem mediada pelo cartaz. A concorrência com a fotografia poderia ter existido, pois o domínio técnico da mesma se dava em nível muito próximo ao da atualidade do séc. XXI, inclusive porque Adolpho, o irmão de Faria, era um parceiro de produçóes e trabalhos que não seria preterido nesse caso. A questão é que as técnicas da pintura, aliadas aos recursos de linguagem da narrativa sequencial gráfica, ampliavam os horizontes da comunicação possibilitada pelos cartazes.

Então, em 1988, Antônio Luiz Cagnin iniciou uma peregrinação em Paris, à procura de informaçóes sobre Faria. A busca compreendeu desde o custodiador de sua vasta produção de cartazes, até a localização de seu estúdio em Montmartre e de seu túmulo:

${ }^{10}$ A invenção do coquetel "Terremoto" (Tremblement de Terre) é atribuída à Toulouse-Lautrec. É uma mistura potente de $1 / 2$ parte de absinto e $1 / 2$ parte de conhaque, servido em taça de vinho sobre cubos de gelo ou batido com gelo em coqueteleira (HENRI, 2018). 
O primeiro passo foi buscar o endereço estampado naquele cartaz de 1896 que se encontra no Brasil, saber onde ficava o ateliê do Affiches FARIA. Encontrei. Com facilidade. Lá estava o prédio no 6 da Steinkerke, uma rua estreita bem defronte à igreja do Sacré Coeur, branca como um grande bolo de neve no alto da butte (colina) de Montmartre (CAGNIN, 2000, p. 10).

A busca incansável de Cagnin revelou, em 2000, que a Companhia Cinematográfica Pathè Frères não custodiara nenhum dos cartazes, assim como não havia uma centralidade em relação à localização dos jazigos que permitisse a localização derradeira de Faria. A importância desse logradouro também se refletia no estabelecimento de contato com os descendentes vivos, e a riqueza de possibilidades: recuperação de originais, documentos pessoais, fotografias, entre outros. Cagnin lograria êxito nas viagens subsequentes, chegando a estabelecer contato com a família na França e até mesmo leva-los a viajar pelo Brasil, para conhecer o berço do ilustre ancestral. Porém, até aquele momento, não se sabia se havia algum acervo custodiados dos cartazes produzidos por Faria.

Somente na proximidade de sua morte o pesquisador Cagnin e, por assim dizer, todos nós os interessados descobrimos quem é a instituição custodiadora do rico acervo de cartazes criados por Faria: o Museu do Louvre. A digitalização de suas obras, a partir de 2004, permitiu que a recuperação fosse feita de forma remota e viabilizou a busca. Cagnin faleceu em 2013, ciente de que Faria teve seu reconhecimento e, afortunadamente, sua produção preservada em um dos mais representativos museus do mundo. Porém, segue até a atualidade o apagamento da identidade brasileira de Faria na França, e temos uma lacuna referente aos estudos de sua produção, tanto lá quanto em terras brasileiras. Enquanto isso, em Paris,

$\mathrm{Na}$ comemoração dos cem anos da sétima arte, em 1995, Paris apresentou ao mundo uma rica exposição que, juntamente com outros eventos, marcavam a contribuição dos irmãos Lumière na criação do cinema. Ali se constata que o brasileiro Cândido de Faria, que foi inegavelmente um dos maiores caricaturistas brasileiros de todos os tempos, produziu o primeiro cartaz de divulgação de películas cinematográficas no ano de 1902 . Na referida exposição, 80 cartazes expostos eram de sua autoria (MAGNO, 2012, p. 230). 
A honra justa e póstuma eleva Cândido Aragonez de Faria a Patrono do Cinema Brasileiro, título que divide com o cineasta Humberto Mauro. Porém, as fontes de pesquisa mais uma vez apagam seu triunfo póstumo, à medida que a própria Academia Brasileira de Cinema abre uma página de "Patronos" para informar à sociedade quem são seus patrocinadores e fomentadores ${ }^{11}$, sem a aparição de Faria ou Mauro.

\section{CONSIDERAÇÕES FINAIS}

Em nossos estudos iniciais buscamos, prioritariamente, contextualizar a atuação de Cândido Aragonez de Faria. Noutro ponto, incitamos a reflexão sobre a presença da estrutura compositiva barroca em suas produçóes. As quais, uma vez percebidas estruturalmente, podem ser identificadas ainda hoje em capas, cartazes e imagens de publicidade e propaganda. A estética barroca como resgatada por Faria, denota a importância não só da composição em si, mas também dos aperfeiçoamentos e ressignificações da mesma num contexto contemporâneo de produção imagética.

Devemos destacar que, ao tratarmos das diagonais barrocas, o fazemos sem demérito algum aos demais estilos artísticos que também as usem. Uma vez que, historicamente, essa característica estética associa-se ao destaque dado às diagonais pelo estilo artístico barroco. Destaque reforçado devido à intensidade emocional das imagens, fruto semiológico do conforto e desconforto visual da disposição dos elementos na composição. Sensações essas causadas, em parte, pela leitura escrita ou visual ocidental, na qual os elementos dispostos nas linhas transversais fazem contraponto com as forças de repulsão e atração das margens e do centro da imagem.

A sensação de desconforto e revés, na verdade, serve para que a observação seja mais atenta, fazendo com que a peça publicitária represente uma experiência prolongada, mais durável e melhor fixada na lembrança. No contexto da eclosão dos espetáculos fílmicos e teatrais populares, esse efeito contribuiu substancialmente para o desenvolvimento do modo

\footnotetext{
${ }^{11}$ Informação disponível em: <http://academiabrasileiradecinema.com.br/patronos/>. Acesso em 16/02/2018.
} 
de produção e de sua mercadologia. Até a atualidade, os chargistas, cartazistas e pintores experientes seguem utilizando esse recurso, de modo acadêmico ou intuitivo.

Por fim, lembramos que o resgate da memória de Cândido Aragonez de Faria e sua produção é importante, tanto para retomar a identidade brasileira de seu trabalho quanto para abrir possibilidades de aprimoramento da composição barroca aplicada às narrativas sequenciais gráficas das mídias impressas e digitais no séc. XXI. 


\section{REFERÊNCIAS}

ARAUJO, Germana G. de; CARVALHO, Beatriz M. de; GUILHERME, Cybelle N.; SANTOS, Jean Carvalho. O Faria: um sergipano na história da ilustração (1866 - 1911). In: Revista do Instituto Histórico e Geográfico De Sergipe. Aracaju, IHGSE, 2017, n.47, p. 131-152.

BENJAMIN, Walter. A obra de arte na era de sua reprodutibilidade técnica. In: LIMA, L. C. Teoria da Cultura de Massa. Rio de Janeiro: Paz e Terra, 1990. p. 209-240.

CAGNIN, Antônio Luiz. O Faria? Conhece? XXIII Congresso Brasileiro de Ciências da Comunicação INTERCOM. Anais... Manaus: Universidade Federal do Amazonas, 2000.

CÂNDIDO ARAGONEZ DE FARIA. In: WIKIPÉDIA, a enciclopédia livre. Flórida: Wikimedia Foundation, 2017. Disponível em: <https://pt.wikipedia.org/w/index.php?title=C\%C3\%A2ndido_Aragonez_de_Faria\&oldid $=49435198>$. Acesso em: 10 fev. 2018.

CARICATURA. In: WIKIPÉDIA, a enciclopédia livre. Flórida: Wikimedia Foundation, 2018. Disponível em: <https://pt.wikipedia.org/w/index.php?title=Caricatura\&oldid=51299289>. Acesso em: 25 fev. 2018.

CHARLES DARWIN. In: WIKIPÉDIA, a enciclopédia livre. Flórida: Wikimedia Foundation, $2017 . \quad$ Disponível em: $<$ https://pt.wikipedia.org/w/index.php?title=Charles_Darwin\&oldid=50572287>. Acesso em: 26 fev. 2018.

CHILVERS, Ian. Dicionário Oxford de arte. São Paulo: Martins, 1996.

FARTHING, Stephen; CORK, Richard. Tudo sobre arte. Rio de Janeiro: Sextante, 2011.

GAUDÊNCIO Junior, Norberto. Um Sergipano em Paris: a arte gráfica de Cândido Aragonez de Faria no fin-de-siècle parisiense (1882 a 1911). Tese (Doutorado em Educação, Arte e História da Cultura) - Universidade Presbiteriana Mackenzie. São Paulo, 2015.

GUIMARÃES, Danielle Virginie Santos. Cândido Aragonez de Faria: um sergipano na Belle Époque. In: Revista Cumbuca. Aracaju, EDISE, 2014, n. 8, p. 4-11.

HENRI DE TOULOUSE-LAUTREC. In: WIKIPÉDIA, a enciclopédia livre. Flórida: Wikimedia

Foundation, 2018.

Disponível em: 
$<$ https://pt.wikipedia.org/w/index.php?title=Henri_de_ToulouseLautrec\&oldid=51345024>. Acesso em: 23 fev. 2018.

LIMA, Herman. Faria. In: História da caricatura no Brasil. Rio de Janeiro: Livraria José Olympio Editora, 1963, v. 2, p. 804-818.

LYON, Howard. A Baroque Composition. 2013. Disponível em: <http://muddycolors. blogspot.com.br/2013/12/a-baroque-composition.html>. Acesso em: set. de 2017.

MAGNO, Luciano. História da Caricatura Brasileira: os precursores e a consolidação da caricatura no Brasil. v.1. Rio de Janeiro: Gala, 2012.

MATTOS, Walter. Pôster Logan e o papel da diagonal em uma composição. Walter Mattos.com. 2017. Disponível em: <https://waltermattos.com/tutoriais/poster-logan-e-opapel-da-diagonal-em-uma-composicao/>. Acesso em: 25 fev. 2018.

MEGGS, Philip B.; PURVIS, Alston W. História da Design Gráfico. Sáo Paulo: Cosac Naify, 2009.

MENEZES, Paulo Roberto de Jesus. Sociedade, Imagem e Biografia na Litografia de Sebastião Sisson. Dissertação (Mestrado em História Social, PPGHIS) - Universidade Federal do Rio de Janeiro. Rio de Janeiro, 2008.

PINTURA DO BARROCO. In: WIKIPÉDIA, a enciclopédia livre. Flórida: Wikimedia Foundation, $2017 . \quad$ Disponível em: <https://pt.wikipedia.org/w/index.php?title=Pintura_do_Barroco\&oldid=50773799>. Acesso em: 16 dez. 2017. 